\title{
Biopolítica y desmemoria en el Santiago posmetropolitano**
}

\author{
Biopolitics and forgetfulness in postmetropolitan Santiago
}

$<$ Resumen>

La condición posmetropolitana de la ciudad de Santiago, permite el establecimiento de formas de reconstitución identitaria que pretenden resistir estéticamente la fragmentación urbana. Esto ocurriría mediante ciertas prácticas cotidianas de diseño doméstico que, al mismo tiempo de generar la ilusión liberal del emprendimiento, colaboran en la consolidación de un imaginario urbano, cuyo efecto final es el olvido simbólico de la violencia política que sostiene el actual panorama de dispersión territorial.

$<$ Abstract $>$

The postmetropolitan condition of Santiago allows the creation of different ways of identity reconstitution, resisting aesthetically the urban fragmentation. This would occur through certain daily practices of domestic design, generating the liberal illusion of entepreneurship, and -at the same time-collaborating on the consolidation of an urban imaginary, whose ultimate effect is a symbolic forgetting of the political violence sustained by the current scenario of territorial dispersion.

<PALABRAS CLAVE >

BIOPOLIITICA / POSMETRÓPOLIS / CARTOGRAFÍA

URBANA / PAISAJES DE HOGAR / IDEOLOGIA

\section{$<K E Y W O R D S>$}

BIOPOLITICS / POSTMETROPOLIS / URBAN MAPPING \& HOMESC APES / IDEOLOGY
En 1984 y de manera irónica, Apple presenta su nuevo modelo de computador Macintosh utilizando el slogan «1984 no será como

1984» exorcizando así la pesadilla orwelliana de la homogeneidad totalitaria. De este modo Macintosh inaugura la lógica de la personalización, en donde el diseño, lejos de concebir un consumo estandarizado o imponer un modo de vida preestablecido, propone un dispositivo que permite la libertad de reconfiguración de la interfase por parte de los usuarios. La lógica de este codiseño o diseño participativo, se ha expandido progresivamente a todo el universo de los utensilios domésticos, y que hoy lidera plataformas virtuales como Fotologs, Facebook o Second-life, otorgando al diseño incluso la capacidad de definir los modos de constitución de la subjetividad. Por lo mismo, no sólo la amplificación de la participación usuaria estaría alentada por el codiseño inaugurado por la era Macintosh, sino también una creciente demanda de

\footnotetext{
Arquitecto y Magíster (c) en Artes mención en Teoría e Historia del Arte de la Universidad de Chile. Profesor e investigador de la escuela de Arquitectura de la Universidad Central, profesor de la Escuela de Filosofía y de Artes Visuales en la Universidad Arcis de Santiago y Valparaíso, Escuela de Arquitectura Universidad de Chile y Escuela de Diseño Universidad Uniacc. Publicaciones destacadas: «La derrota de lo cotidiano. Ciudad, arquitectura y temporalidad». Revista de Teoría del Arte, Facultad de Artes, Universidad de Chile, 2006; "Contingencia y estéticas de la interrupción. Posibilidades para un futuro auténtico de la ciudad contemporánea», Universidad de Chile y Goethe Institut, 2008; "La ciudad como voluntad y representación». Centro de Estudios Arquitectónico Urbanísticos y del Paisaje (CEAUP), Facultad de Arquitectura, Universidad Central, 2008; «Entre carne y piedra: Notas para una condición postsomática de la ciudad contemporánea», publicado en «Estéticas de la intemperie. Lecturas y acción en el espacio público» Serie seminarios de la colección Escritos de Obras. Escuela de Artes Visuales, Universidad de Chile 2010, entre otros.

** El presente texto fue presentado por el autor en el III Coloquio Nacional de Biopolítica, «Crisis, miedos y sociedad de control» realizado en octubre de 2009 en la Escuela de Artes Visuales de la Universidad de Chile, y en una versión más extendida, en el Congreso Nacional de Filosofía en septiembre de 2009, Biblioteca de Santiago. Este artículo, además, representa el marco conceptual general del proyecto de investigación «Paisajes del cotidiano doméstico aspiracional. Mitología neoliberal del Santiago posmetropolitano», que actualmente el autor se encuentra desarrollando en la Escuela de Arquitectura de la Facultad de Arquitectura y Paisaje de la Universidad Central de Chile.
} 
competencia estética de los sujetos. La interpelación que el sistema de artefactos contemporáneos cibernetizados hace a aquellos, es a invertir en capital simbólico para efectos de realizar sus idoneidades estéticas y usuarias en la personalización de los utensilios. Es precisamente en este punto donde debemos introducir el carácter eminentemente biopolítico de las prácticas de codiseño.

Uno de los aportes centrales del neoliberalismo, nos advierte Foucault en el NACIMIENTO DE LA BIOPOLITICA, fue la reintroducción del trabajo en el análisis económico aunque transfigurado bajo la modalidad del «capital humano». Antes que nada, la fuerza de trabajo es una idoneidad física e intelectual indiscernible del cuerpo trabajador, que debe ser utilizada estratégicamente para obtener una renta. Se trata, por tanto, de un capital-idoneidad que en su administración racional, convierte al trabajador en una empresa para sí mismo․ Por ello, el análisis neoliberal del capital humano se caracteriza, particularmente, como una red de identificaciones entre producción y consumo.

Ad-hoc a la definición empresarial del yo y realizada magistralmente en las prácticas del codiseño, esta lógica biopolítica de un consumo instrumental personalizado, aparentemente conduciría a una constante disolución de los vínculos sociales, con el consiguiente estado de privatización y atomización del cotidiano contemporáneo. Justamente esto pareciera ser el efecto microcósmico que acontecería en la urbe actual en lo que Edward Soja denomina como Posmetrópolis. Esta condición estaría dada por la catástrofe de disolución de complejo metropolitano que se caracteriza primordialmente como la progresiva fragmentación y dispersión de la ciudad tras la modernización neoliberal implementada desde fines de la década de los '70. En buenas cuentas, ya no es posible hablar de la ciudad como una construcción unitaria bajo lógicas plenamente concatenadas, más bien se estaría consolidando una agregación de realidades urbanas con lógicas de funcionamiento independientes, producto del creciente desacoplamiento estructural y funcional entre una periferia urbana cada vez más autosuficiente y la ciudad tradicional representada por el centro histórico y los emplazamientos pericéntricos ${ }^{2}$. Este desacoplamiento de cinturón suburbano respecto de la metrópolis tradicional se debe, entre otras causas, al avance de la ideología norteamericana del neourbanismo, caracterizado por la tendencia a la generación de modos de vida periféricos, pseudobucólicos y antimetropolitanos en donde se pregona la obsesión por la seguridad ciudadana y la higienización tanto social como estética de los ambientes residenciales. Quizás el ejemplo más elocuente del neourbanismo norteamericano está dado por su emblema fundacional en el estado de Florida, en el célebre Seaside que no por casualidad se convirtió en el escenario de filmación del SHow DE TRUMAN en donde se expone, metafóricamente, la posibilidad de realización de toda la vida cotidiana con total prescindencia de las dinámicas metropolitanas.

Ahora bien, este astillamiento de la realidad posmetropolitana produciría, correlativamente, el estadillo disciplinar del urbanismo, el que se ve inevitablemente en serios aprietos a la hora de representar la ciudad bajo una intelección unitaria. Precisamente todos los énfasis experimentales relativos a la representación de la urbe contemporánea están inscritos en esta catástrofe de disolución de la unidad del complejo urbano. A este respecto se puede destacar el trabajo de Valencia, Llanos y Lehmann, destinado a reconstruir las dinámicas posmetropolitanas, por medio de lo que ellos denominan "cartografías urbanas» ${ }^{3}$. Este modelo consistiría básicamente en la definición de un conjunto múltiple de capas de realidad urbana que coexisten en completo traslapo y que emergen precisamente por medio del dispositivo cartográfico, asumiendo de manera decidida el carácter fractal y desestructurado de la ciudad neoliberal. En este sentido, los autores identifican al menos seis cartografías básicas de la ciudad de Santiago 4 . La primera se denomina la nueva periferia del consumo, cada vez más independizada en donde coexisten los conjuntos residenciales, los centros comerciales y las vías de circulación rápida. La segunda cartografía corresponde a la ciudad interior o la ciudad pendiente, constituida por

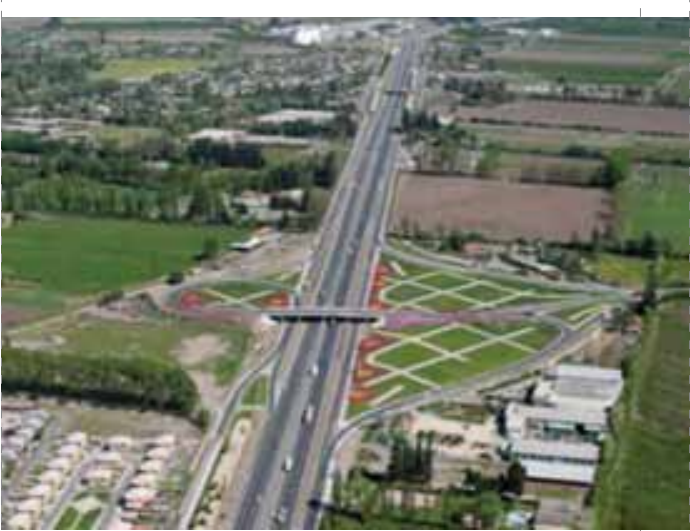

[Cartografías de Santiago. Valencia, Llanos. Universidad [entral]. La nueva periferia de consumo. Acceso sur de Santiago.

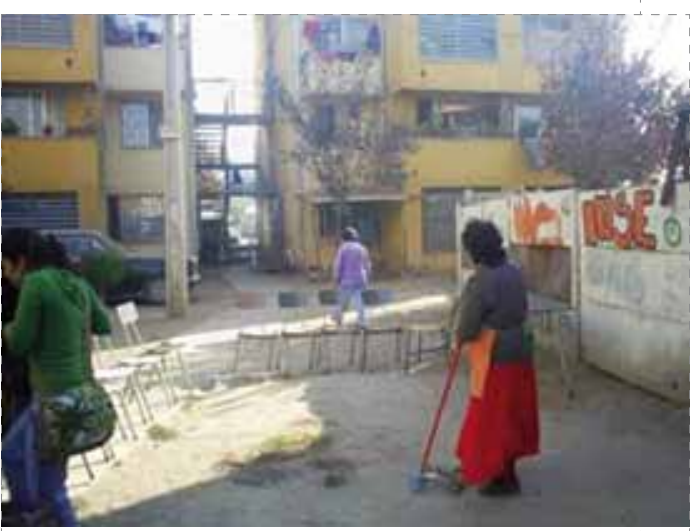

[Cartografías de Santiago Valencia, Llanos. Universidad [entral]. La periferia interior o la ciudad pendiente Cerro Navia.

un cinturón de comunas periféricas endógenas que se caracterizan por su condición de precariedad socioespacial siendo la mayoría fruto de las erradicaciones realizadas por la dictadura durante la década de los ochenta. La tercera cartografía corresponde a la ciudad aspiracional o la renovación urbana del pericentro, caracterizada por el imaginario

Foucault, Michel. Nacimiento de la biopolítica. Curso en el Collège de France (1978-1979). Buenos Aires: Editorial Fondo de Cultura Económica, 2007, pág. 264.

Soja, Edward. «Postmetrópolis. Estudios críticos sobre las ciudades y las regiones». Madrid. Traficantes de sueños, 2008.

Valencia Marco Lehmann Karen. Lano, José «Cartografías de ciudad Discursos, culturas y representaciones urbanas en Santiago. 1990-2000» Revista Electrónica DU \& P.

Diseño Urbano y Paisaje Volumen I № 3. Centro de Estudios Arquitectónicos, Urbanísticos y del Paisaje, Universidad Central de Chile, Santiago, Chile, abril 2008.

Valencia, Marco; Llano, José. Cartografías urbanas Santiago Montevideo. Revista Electrónica DU \& P. Diseño Urbano y Paisaje Volumen V N 13. Centro de Estudios

Arquitectónicos, Urbanísticos y del Paisaje, Universidad Central de Chile, Santiago, Chile, abril 2008. 

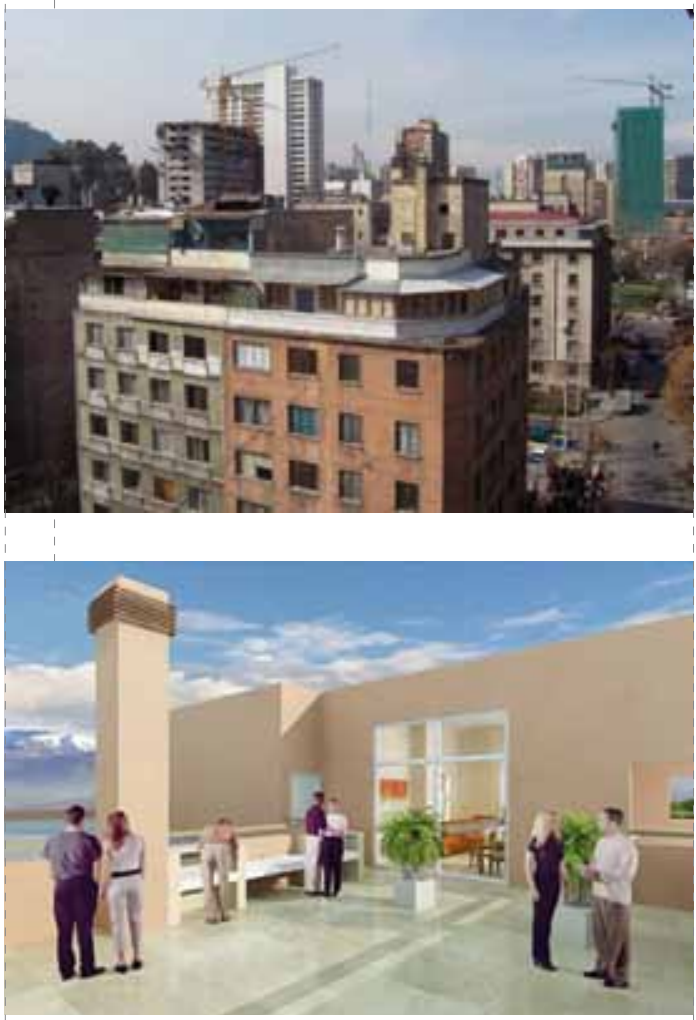

[Cartografías de Santiago. Valencia, Llanos. Universidad [entrall. La ciudad aspiracional o la renovación urbana de pericentro

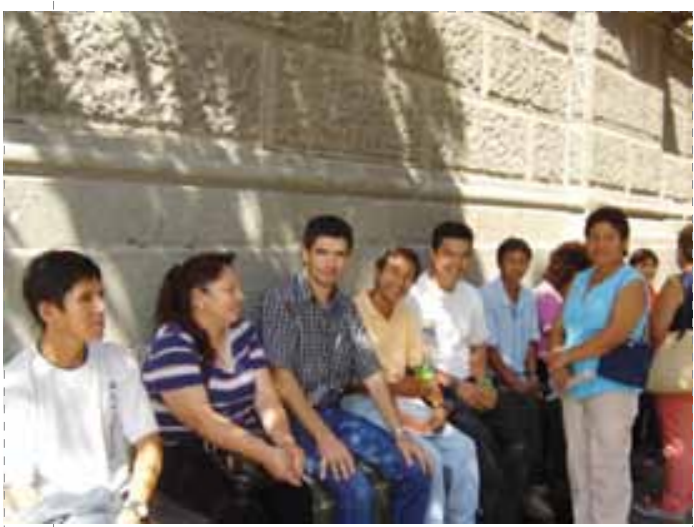

[Cartografías de Santiago. Valencia. Llanos. Universidad [entral]. La ciudad multicultural como resignificación del casco histórico. inmobiliario asociado a la deseabilidad social impuesta desde los dispositivos publicitarios, fuertemente influenciados por el discurso del neourbanismo norteamericano. La cuarta cartografía estaría dada por la ciudad multicultural como resignificación del casco histórico, en donde se intenta registrar los modos de apropiación simbólico-territorial por parte de inmigrantes, minorías nacionales y étnicas. La quinta es la ciudad como máquina paranoica, constituida por el emplazamiento de las lógicas de seguridad ciudadana, el mapeo de la delincuencia y el reparto de los dispositivos de vigilancia. Por último, estaría la ciudad de lo público, caracterizada por la emergencia de lo multitudinario y lo masivo, entendidas como lógicas de subjetivación política que acontecen en el momento de su visibilización en el espacio público urbano.

Lo que todas estas cartografías pretenden finalmente confirmar es la impertinencia de concebir a la ciudad contemporánea como un territorio homogéneo a partir del cual sea posible la constitución de una ciudadanía universal. El astillamiento de la ciudad en su dispersión cartográfica, más bien vendría a impedir el reconocimiento identitario por parte de los habitantes respecto de una supuesta totalidad urbana. Precisamente, esta sensación de extrañamiento constante de los sujetos posmetropolitanos es lo que Celeste Olalquiaga define bajo el nombre de psicastenia, entendida como un fenómeno de malestar ante la sensación de estar literal y figuradamente "perdido en el espacio»" tras la creciente desorientación simbólicoespacial padecida por la imposibilidad de los habitantes de figurar a la ciudad como un total. Sin embargo, a pesar de este fenómeno producto de la modernización neoliberal, habría un par de cartografías en donde se produciría más bien el efecto contrario, es decir, lo que podríamos llamar un fenómeno "antipsicasténico» que las desmarcaría, virtualmente, de las otras cartografías mencionadas. Esto es lo que ocurriría principalmente con la nueva periferia del consumo y su correlato interior, la ciudad aspiracional que comparten, como eje común, las lógicas del neourbanismo norteamericano. En otras palabras, lo que estas dos cartografías ponen de manifiesto, es la tendencia a contracorriente respecto a la tradicional imagen de progresiva desintegración territorial atribuida al neoliberalismo y que ha sido constantemente sostenido por el discurso típicamente posmoderno de la fragmentación.

¿De qué modo los perfiles cartográficos de la ciudad aspiracional y la periferia del consumo desarrollan un efecto antipsicasténico? La plausibilidad de esta tesis estaría confirmada, de alguna manera por la intención de una totalización estética que operaría como un continuo que enlaza todo el marco de desenvolvimiento cotidiano de tales cartografías, desde el espacio público hasta la intimidad domiciliaria. Esta continuidad estética bien podría reconocerse bajo la categoría de «paisaje», entendido precisamente como dominio de totalización ambiental, en donde la heterogeneidad de los elementos queda sometida a la identidad de la mirada. Javier Maderuelo lo define de esta manera: "El Paisaje no es, por lo tanto lo que está ahí, ante nosotros, es un concepto inventado o, mejor dicho, una construcción cultural» ${ }^{6}$. Pues bien, el paisaje tendría una condición antipsicasténica por cuanto implica siempre un observador que proyecta integración sobre su entorno al tiempo de ser invitado, simultáneamente, a experimentar la unidad por medio del efecto que el paisaje, configurado por su propia mirada, termina finalmente ejerciendo en aquél. Este doble reenvío de integralidad entre el observador y su objeto, redunda en un sentimiento de familiaridad e identificación con aquella totalidad constituida paisajísticamente. Quizás el antecedente específicamente estético de esta particular identificación unitaria, es posible localizarlo en la invención de un dispositivo de representación del siglo XVIII por parte del escocés Robert Barker, conocido como "panorama». El objetivo de éste era producir, por medio de artilugios visuales y técnicos, una imagen circular que el pintor-observador construye hacia los cuatro puntos cardinales desde un punto central, desplegando esta imagen a través de gigantescos planos pictóricos, en salas también circulares consiguiendo, de este modo, obligar al espectador a una visión totalizadora. De la tradición paisajística del panorama podemos rescatar dos elementos fundamentales. El primero dice relación con la subordinación de su artificio técnico al carácter de espectáculo, el segundo se vincula a la incorporación del movimiento en la captura de la totalidad. Precisamente la ciudad aspiracional y la periferia del consumo ofrecen el carácter paisajístico del panorama 
puesto que se emparientan en sus diseños a la tradición de los parques temáticos -cuyo paradigma fundacional es Disneyland de 1955 - y cuya característica más elocuente es la subordinación de los recursos técnicos a la función espectacular. Por otra parte, y quizás lo más fundamental, es que la conformación del efecto paisaje propio de estas cartografías es realizado por medio del desplazamiento espacial: estos perfiles de ciudad se constituyen a través de un sistema integrado que unifica el marco residencial, los medios de circulación de alta velocidad

-autopistas o transporte público- y los megacentros comerciales y de servicios, quienes, en su conjunto, adquieren una dimensión panorámica a través del recorrido cotidiano que va desde el domicilio hasta el centro comercial (mall).

Ahora bien, este sistema paisajístico presenta unidad estética, por cuanto todos sus elementos han sido cuidadosamente diseñados para un comportamiento unitario de la mirada, evitando toda interrupción sintagmática, tal como suele ocurrir en la oferta visual de los parques temáticos. Sin embargo, en medio de este diseño total que va desde el centro comercial hasta el espacio residencial, claramente digitado por la estética del neourbanismo, parece quedar un único cabo suelto en la cadena significante. Aparentemente, el espacio interior de la vivienda unifamiliar mantendría una cierta autonomía respecto de los formatos profesionales del diseño que hilvanan el resto del sistema paisajístico, dado que su disposicionamiento ambiental estaría por completo bajo el arbitrio de los moradores. Justamente, es esta ilusión de autonomía la que viene a ser completamente alentada por las prácticas de codiseño que han colonizado en su totalidad el ambiente doméstico.

Podemos reconocer, en este sentido, dos vías fundamentales mediante las cuales se realizan dicha colonización de lo residencial y que precisamente estimulan la inversión de capital simbólico por parte de los sujetos conminados a diseñar sus domicilios. Por un lado, se encuentra toda la oferta de productos y utensilios para el hogar que recogen el espíritu de la personalización usuaria, oferta realizada y supervisada por las propias megatiendas que componen parte del paisaje de la ciudad aspiracional (Easy, Home Center, Casa \& Ideas, etc.). Por otro lado, se encuentra toda la maquinaria editorial destinada a entregar los códigos necesarios para el buen desempeño de las prácticas de codiseño doméstico. Nos referimos fundamentalmente a revistas de decoración adjuntas como suplementos de la prensa de gran tiraje y altamente prestigiadas
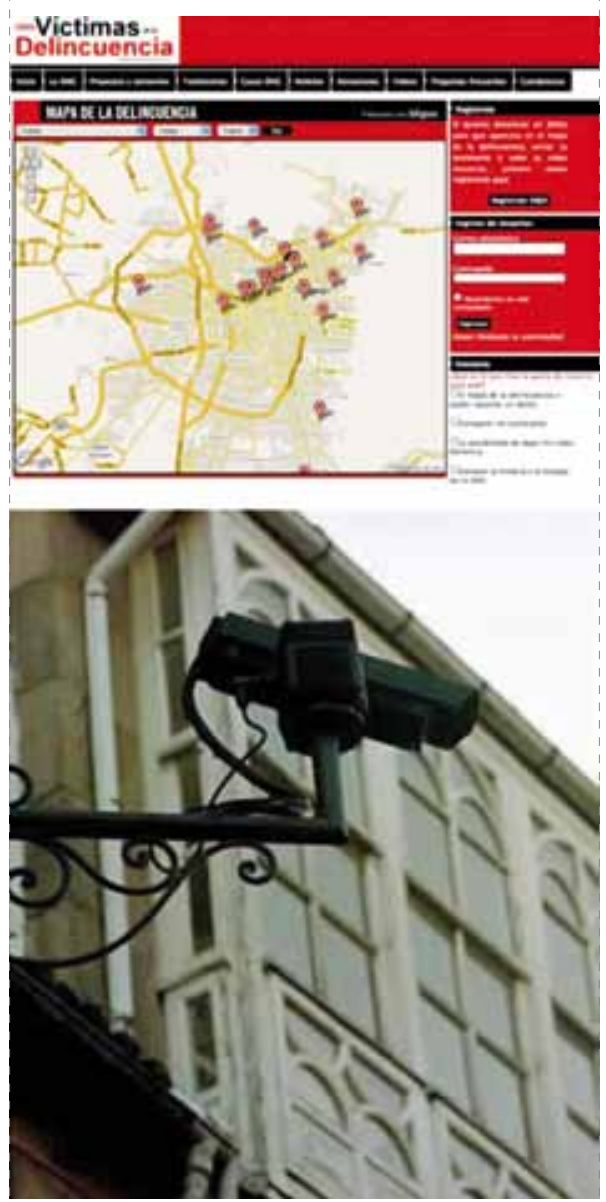

[Cartografías de Santiago. Valencia Llanos. Universidad [entral].

La ciudad como máquina paranoica

(Vivienda y Decoración; +decoración, etc.), vinculadas ideológicamente a los mismos sectores empresariales propietarios de las megatiendas para el hogar. Pues bien, la complementación entre la oferta de productos y la educación estética mediáticamente dirigida, permiten generar las competencias adecuadas para que los sujetos, más allá de un comportamiento de consumo estandarizado o pasivo de estilos de vida, desarrollen autónomamente su idoneidad estética para disponer el ambiente hogareño de acuerdo a sus propios requerimientos y gustos. Por cierto, la dimensión biopolítica de esta materialización de la idoneidad estética de los sujetos a través del diseño doméstico, se sustenta en

Candina, Azun; «Por una vida digna y decorosa. Clase media y empleados públicos en el siglo xx chileno». Esfera de Papel Libros S.A., Facultad de Filosofía y Humanidades, Universidad de Chile, 2009. la necesaria inversión en capital simbólico que éstos actualizan en el agenciamiento de sus entornos íntimos, al permitirles reafirmar su condición de empresarios de sí mismos a través de la contemplación del resultado ambiental conseguido. Sin duda, el destinatario interpelado en este tipo de prácticas, es la nueva clase media que emerge tras la progresiva implosión de lo que históricamente fue el núcleo de su fundación: el sector público ${ }^{7}$. Bajo el influjo de la modernización neoliberal, la figura del empleado público debe ser sustituida por nuevos dispositivos que permitan reconstituir su identidad de clase, esta vez, mediante la investidura imaginaria de «emprendedor». 


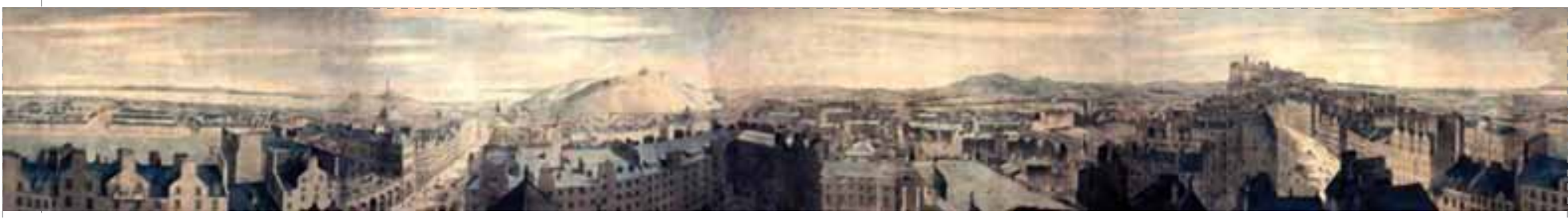

Panorama de Edimburgo. 1792. Robert Barker

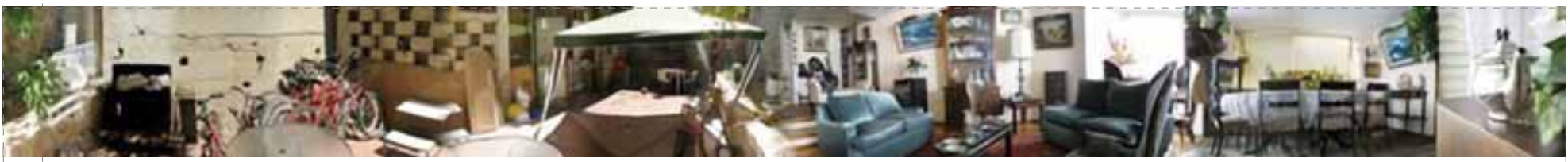

Homescapes. Carlos Silva. 2008

Sin embargo, la ilusión de autonomía del diseño hogareño clase-mediano, se ve completamente cuestionada cuando consideramos el efecto final que dicha práctica involucra, al ser inscrita en el contexto general de la cadena significante que constituye el paisaje de la ciudad aspiracional. Precisamente, las operaciones estéticas aparentemente autónomas de las prácticas de codiseño doméstico, no hacen sino sellar definitivamente dicha cadena, al poblar el último nicho no intervenido por el diseño profesional como pareciese ser el interior residencial. El resultado que este fenómeno arroja, es la constitución de una completa continuidad estética que ahora va desde el interior hogareño hasta el espacio público de los centros comerciales, continuidad articulada como panorama paisajístico a través del diario ir y venir entre lo privado y lo público. El efecto antipsicasténico se consolida justamente por este encadenamiento estético-visivo, cuando cotidianamente se percibe siempre el mismo fenotipo ambiental, generando el sentimiento de familiaridad e identidad emotiva con la totalidad del perfil de la ciudad aspiracional. Efectivamente, lo aspiracional de esta manifestación urbana neoliberal, consiste en la promesa de integración y familiaridad de un hábitat que pretende instaurarse como perfil hegemónico de la pertenencia comunitaria urbana.

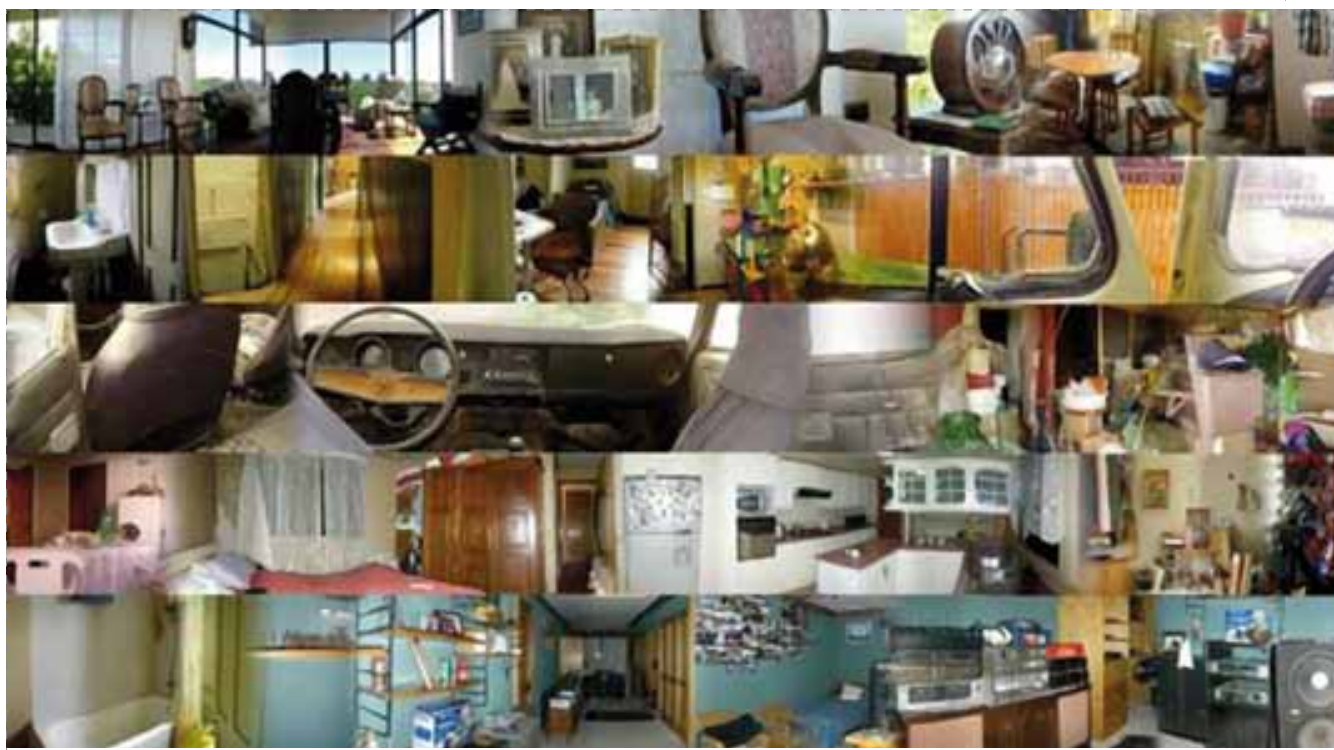

Homescapes. Carlos Silva. 2008.

Ésta es la dimensión que se deja leer en los trabajos del artista visual chileno Carlos Silva, específicamente en los dispositivos de registro de los ambientes domésticos que denomina "Homescapes», o paisajes de hogar ${ }^{8}$. En lo relativo a su desempeño cotidiano, el interior doméstico se caracteriza por lo «a-la-mano» debido a la falta de distancia entre el usuario y su entorno instrumental. El resultado de ello, es la invisibilización que el ambiente

8 Cfr. Silva, Carlos; http://carlos--silva.blogspot.com

Cfr. Heidegger, Martin; «Ser y Tiempo» Editorial Universitaria, Santiago, 1997. «Ser-a-la-mano» es la traducción del término Zuhandenheit que designa el modo de comparecencia cotidiana de los entes, siendo un régimen de la sensorialidad que es indisociable de la significación instrumental de los mismos. A diferencia de la Vorhandenheit o «ser-a-la-vista» que revela a los entes en su pura imposición perceptual, la Zuhandenheit de algún modo los oscurece, al concebirlos completamente sumergidos y subordinados a la precomprensión que designa el lugar instrumental que cada ente reviste en el entorno cotidiano. 


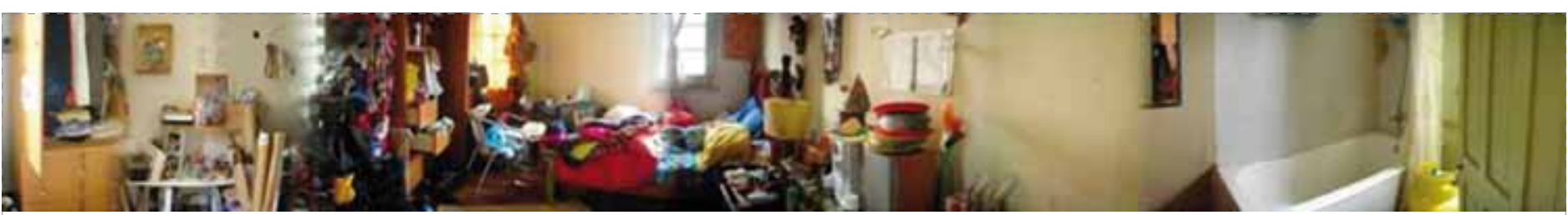

Homescapes. Carlos Silva. 2008

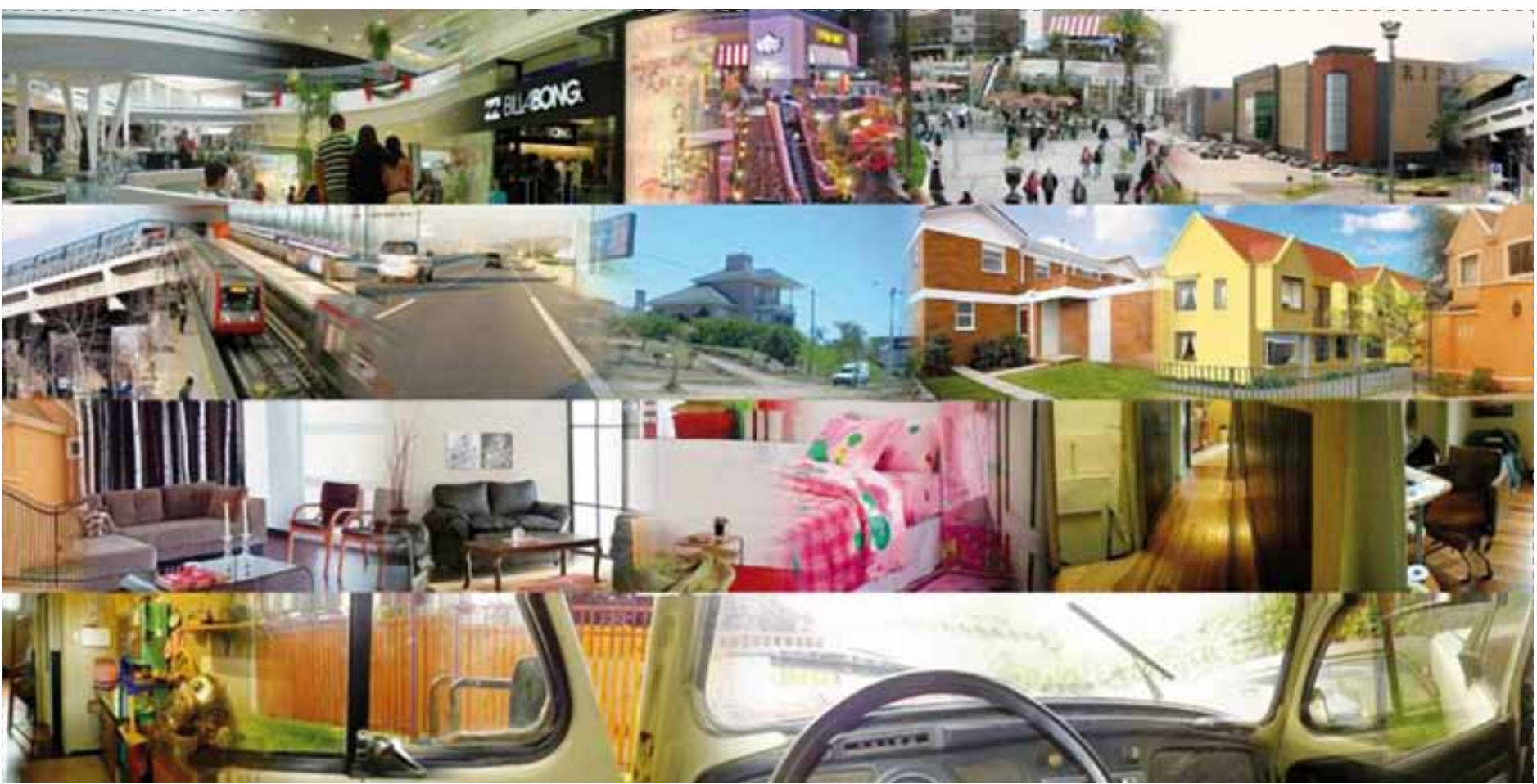

Panorama de ciudad aspiracional con homescapes. Carlos Silva, 2009

hogareño adquiere en el uso diario. En alguna medida, los homescapes pretenden revertir esta obliteración cotidiana, haciendo resaltar el carácter visivo del ambiente aludiendo la tradición paisajística del panorama, en donde los objetos se van enlazando en una construcción sintagmática que permite, a su vez, destacar sus articulaciones de continuidad formal.
Pues bien, en el contexto resultante de la condición posmetropolitana del Santiago transicional ${ }^{10}$, el diseño doméstico practicado cotidianamente por los sujetos inscritos en el orden cartográfico de la ciudad aspiracional, constituye una dimensión biopolítica al implicar un proceso de inversión constante de competencias e idoneidades estéticas que conduce a sellar un «efecto de paisaje», al generarse un continuum que enlaza la totalidad del perfil cartográfico, incluyendo, esta vez, al propio interior doméstico. Más aún, esta condición bien podría llegar a caracterizar un rasgo eminentemente mítico de la ciudad aspiracional. Justamente y tal como nos dice Barthes, el mito «tiene a su cargo fundamentar como naturaleza lo que tiene intención histórica; como eternidad lo que es contingencia... el mito está constituido por la pérdida de la cualidad histórica de las cosas: las cosas pierden en él el recuerdo de su construcción» ${ }^{11}$. En este sentido, la

\footnotetext{
10 El concepto de «transición» no es comprendido aquí únicamente bajo el sentido común del término, generalmente utilizado para identificar el proceso de reformas democráticas impulsadas por los gobiernos concertacionistas. Más bien alude a lo que Thayer define como el tránsito del Estado al Mercado, transcurso que involucra el amplio marco de transformaciones estructurales producidas por la modernización neoliberal, iniciada mucho antes por la dictadura. Thayer, Willy. «La crisis no moderna de la universidad moderna» Editorial Cuarto Propio, Santiago, 1996.

Barthes, Roland. «Mitologías». Editorial Siglo XXI, Buenos Aires, 2000, pág. 238.
} 


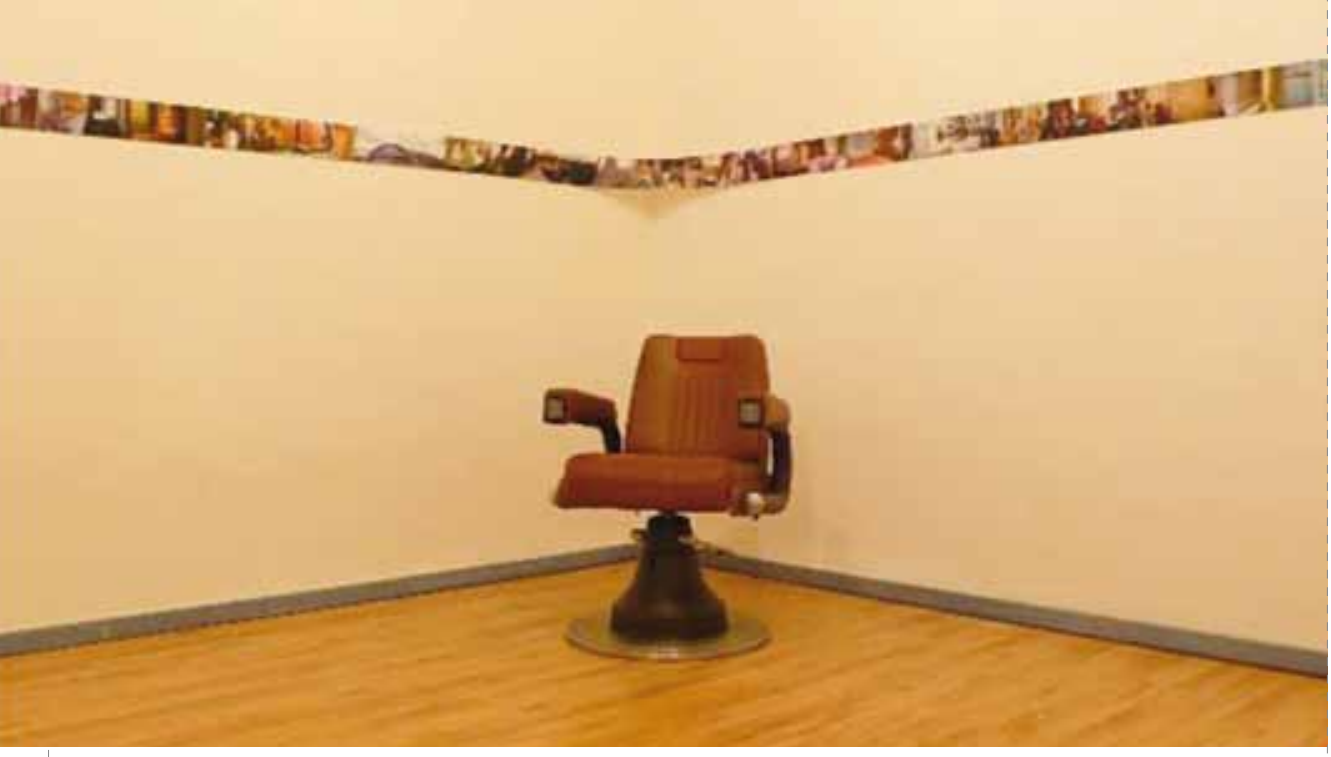

Homescapes. Carlos Silva. 2008

labor primordial del mito es el reemplazo del tiempo por el espacio, de la diacronía por la sincronía, en buenas cuentas, de la Historia por la contingencia cotidiana. La ciudad aspiracional devenida paisaje articulador de las prácticas domésticas de diseño y su continuidad panorámica con el espacio público, puede constituir un régimen mítico si tomamos tres de los aspectos más elocuentes que lo caracterizan. Primeramente el mito involucra siempre un efecto de totalización, que esta vez se ve ejercido en el orden cotidiano como continuidad paisajística del diseño que cubre todo el perfil visual de la ciudad aspiracional. En segundo lugar y como consecuencia de lo anterior, el mito apela a la fundación de una comunidad, que aquí se ve realizada por medio del reconocimiento social de competencias estéticas comunes de los sujetos aspiracionalmente movilizados a demostrarlas en el interior hogareño -la nueva clase media-y, por último, la consecuente tendencia a la obliteración de los procesos diacrónicos que han hecho posible la constitución misma del mito, que en este caso vendría a ser puesto en operación por el propio "efecto de paisaje». Justamente y por obra de este efecto, la vida cotidiana se constituye, dentro de la ciudad aspiracional, en el ámbito dominante de la conciencia existencial de las nuevas subjetividades posmetropolitanas que la habitan, borrando progresivamente por medio de las operaciones del diseño doméstico, el horizonte histórico en el cual se inscriben y que permitirían la inteligibilidad política de tal fenómeno. Esto no sería sino una consecuencia del olvido simbólico que el modelo neoliberal practicaría cotidianamente a nivel del imaginario urbano, precisamente para reprimir la violencia política que le dio origen oscureciendo, al mismo tiempo, la conciencia de la transfiguración identitaria de la clase media como el efecto de subjetivación primordial de dicha violencia.

A partir del agenciamiento biopolítico propio de las prácticas de codiseño doméstico que contribuyen a la edificación de un paisaje mítico podemos, finalmente, decir que el modo antipsicasténico que el neoliberalismo posmetropolitano llega a conformar, es fundamentalmente una ideología, en el preciso sentido que Slavoj Žižek concede al término. "La ideología -nos dice- no es simplemente una 'falsa conciencia', una representación ilusoria de la realidad, es más bien esta realidad a la que ya se ha de concebir como 'ideológica' - 'ideológica' es una realidad social cuya existencia implica el no conocimiento de sus participantes en lo que se refiere a su esencia- es decir, la efectividad social, cuya misma reproducción implica que los individuos no sepan lo que están haciendo» ${ }^{12}$. Por lo mismo, seremos capaces de afirmar que el mito neoliberal es justamente una ideología por cuanto no se constituye como una quimera deformante que nuble las conciencias de los sujetos, sino una praxis territorial en donde su mítica se estructura fundamentalmente como paisaje urbano. La ideología, más allá de ser un mero conjunto de ideas o convicciones, es una forma que, en nuestro caso, se desplegaría como concreción material de un específico ordenamiento sintagmático de los objetos que pueblan el perfil citadino.

De este modo, es la propia estructuración de la realidad cotidiana la que ejerce un efecto de desconocimiento sobre las lógicas que la constituyen; en otras palabras, es la propia forma del sintagma ambiental, la que, al igual que la forma del sueño, obedece a una elaboración necesaria para efectuar la represión y ocultamiento de aquello que, justamente, comanda a dicha elaboración. En este sentido, lo que la práctica del codiseño doméstico reprime no es la velada complicidad del diseño profesional con la manipulación mediática inmobiliaria o comercial que la sustenta, sino el trauma que finalmente organiza toda la cadena significante del paisaje y cuyo efecto no hace sino disimular las condiciones de una violencia urbana y política constante que opera en el resto de la psicasténica posmetrópolis y que posibilitan la emergencia del cotidiano aspiracional en tanto modo de totalización, integración y ocultamiento mítico. Si decimos que la represión ideológica se realiza en la forma, ésta se constituye sólo cuando adquiere la dimensión de lo total. Pues bien, el acceso a la totalidad de la forma ocurre cuando el único espacio aparentemente liberado del diseño profesional sistemático -como parece ser el de la discrecionalidad estética del sujeto domiciliado- también es leído como pura forma, y no como autonomía en la ambientación facultada por el uso de utensilios de codiseño. Precisamente el homescapes es el recurso que haría resaltar el carácter visivo del ambiente doméstico bajo la tradición paisajística del panorama, en miras a evidenciar su continuidad con el resto del sistema visual de la ciudad aspiracional, revelando la Gestalt que la constituye. El punto crucial no consiste en descubrir el secreto tras su forma sino el secreto de su forma. Lo que los seres domiciliados hacen en concreto, es borrar los fundamentos de su acción diseñadora en el momento mismo de poner en práctica su idoneidad estética al personalizar sus hogares. Este fenómeno tendría el carácter de síntoma, por cuanto se trata de una formación cuya consistencia 
implica un cierto desconocimiento por parte del sujeto involucrado: el sujeto puede gozar su síntoma sólo en la medida en que su lógica se le escape. En este sentido, lo que los homescapes vienen a revelar es precisamente el síntoma, en tanto permiten construir la forma del sintagma global que estructura a la ciudad aspiracional, evidenciando la contradicción entre su calculado diseño de lo público y la supuesta autonomía de lo privado doméstico. Bajo este contexto, gozar el síntoma consistiría en materializar la cualidad biopolítica de un yo empresarial que invierte en capital simbólico para efectos de realizar su emprendimiento estético a través del diseño de su entorno hogareño.

Por consecuencia, el nivel fundamental de la ideología, no es el de una ilusión que enmascare el estado real de las cosas, sino de una fantasía (inconsciente) que estructura nuestra propia realidad social. No se trata de que los sujetos no sepan que la ciudad aspiracional a la cual pertenecen es un simulacro, lo que ocurre es que, aún sabiéndolo, continúan prolongando su artificiosidad. No se debe, en definitiva, a que crean ilusoriamente que no habitan en un parque temático, como pudo ocurrirle en un principio al desdichado Truman. Por el contrario, la creencia, lejos de ser un estado íntimo puramente mental, se materializa siempre en una actividad social efectiva: la creencia sostiene la fantasía que regula la realidad social. «Ellos» ya no creen (saben que es una ilusión), pero las cosas creen por ellos, la creencia, no es interior, sino es exteriorizada, objetual. Žižek, ilustra esta condición eminentemente objetual de la creencia mediante el siguiente ejemplo: «vamos a recordar un fenómeno que es bastante frecuente en los espectáculos populares de televisión o series: "la risa enlatada». Después de algún comentario supuestamente ingenioso o divertido, se escucha la risa y el aplauso incluido en la banda de sonido del espectáculo (...) ¿Por qué esta risa? (...) la única respuesta correcta sería que el Otro -encarnado en el aparato de televisión- nos está descargando de la obligación de reír, ríe en vez de nosotros. Así que, aun si cansados de un fatigoso día de trabajo estúpido, nos pasamos la tarde mirando amodorrados la pantalla de televisión, después podemos decir que, objetivamente, por medio de otro, nos la pasamos realmente bien» ${ }^{13}$. La creencia en la personalización y la autonomía lograda por la inversión en capital simbólico que proporciona idoneidad para diseñar el entorno doméstico, no es necesariamente algo que los usuarios deban asumir. No es necesario creerle a Macintosh y su exorcismo de 1984. Son los propios objetos, en tanto posibilitados para incorporar la participación del usuario mediante el codiseño, quienes encarnan materialmente tal creencia. Independientemente si lo creo o no, soy objetivamente autónomo, puesto que los objetos agenciados bajo la modalidad del codiseño comportan la posibilidad de ejercer mi libertad creativa. Ésta sería la razón por la cual, a pesar de ser concientes del carácter de simulacro de la ciudad aspiracional en la que viven, los sujetos continúen prolongando su artificialidad, dado que los artefactos domésticos que los rodean se encargan de realizar su autonomía, del mismo modo en que la televisiva risa enlatada, ríe por nosotros.

"La ideología -nos dice Žižek- designa (no una parcialidad que oculta la totalidad de las relaciones sociales) antes bien, una totalidad que borra las huellas de su propia imposibilidad ${ }^{14}$. Precisamente, el paisaje de la ciudad aspiracional neoliberal, no es sino dicha totalidad, en donde el real-traumático que la estructura se ha vuelto inaccesible. Lo que bajo el entusiasmo de arreglar el interior doméstico o el simple descansar en los objetos que hacemos ingresar en él vienen a ocultar cotidianamente, es el trauma urbano de la dictadura que ha posibilitado la instalación del neourbanismo y la promesa de emancipación doméstica que otorga el uso creativo de nuestros amables artefactos. En otras palabras, la desmemoria del trauma de la violencia política que funda el mito neoliberal no es un estado de inconciencia, sino una praxis desenvuelta en la más gigantesca empresa de movilización cotidiana: es un paisaje urbano que ha conseguido cruzar el umbral de lo residencial para acomodarse, finalmente, en nuestras propias e inocentes prácticas de diseño hogareño.
«Entre carne y piedra. Notas para una condición postsomática de la ciudad contemporánea», publicado en ESTÉTICAS DE LA INTEMPERIE. LECTURAS Y ACCIÓN EN EL ESPACIO PÚBLICO, SERIE SEMINARIOS DE LA COLECCIÓN ESCRITOS DE Obras. Escuela de Artes Visuales, Universidad de Chile 2010

\section{Referencias bibliográficas}

Barthes, R. «Mitologías». Editorial Siglo XXI, Buenos Aires, 2000.

Candina, A. «Por una vida digna y decorosa. Clase media y empleados públicos en el siglo xx chileno». Esfera de Papel Libros S.A., Facultad de Filosofía y Humanidades, Universidad de Chile, 2009.

Foucault, M. «Nacimiento de la biopolítica. Curso en el Collège de France (1978-1979)». Buenos Aires: Editorial Fondo de Cultura Económica, 2007

Heidegger, M. «Ser y Tiempo» Editorial Universitaria, Santiago de Chile, 1997.

Maderuelo, J. «El paisaje. Génesis de un concepto». Madrid: Abada editores, 2005.

Soja, E. «Postmetrópolis. Estudios críticos sobre las ciudades y las regiones». Madrid: Traficantes de sueños, 2008.

Thayer, W. «La crisis no moderna de la universidad moderna». Editorial Cuarto Propio, Santiago de Chile, 1996

Valencia, M; Lehmann, K. Llano, J. «Cartografías de ciudad. Discursos, culturas y representaciones urbanas en Santiago. 1990-2000. "Revista Electrónica DU \& P. Diseño Urbano y Paisaje Volumen I No 3. Centro de Estudios Arquitectónicos, Urbanísticos y del Paisaje, Universidad Central de Chile, Santiago, Chile, abril 2008.

Valencia, M; Llano, J. «Cartografías urbanas Santiago Montevideo». Revista Electrónica DU \& P. Diseño Urbano y Paisaje Volumen V No 13 . Centro de Estudios Arquitectónicos, Urbanísticos y del Paisaje, Universidad Central de Chile, Santiago, Chile, abril 2008

Žižek, S. «El sublime objeto de la ideología». Buenos Aires, Siglo XXI, 2009.

13 Ibíd., pág. 64

14 Ibíd., pág. 81 